ERC Working Papers in Economics 16/11

September / 2016

\title{
The Scope of Auctions in the Presence of Downstream Interactions and Information Externalities
}

\author{
Onur A. Koska \\ Department of Economics, Middle East Technical University, Ankara, Turkey \\ E-mail: koska@metu.edu.tr \\ Phone: + (90) 3122103046 \\ İlke Onur \\ School of Commerce, Division of Business, University of South Australia, \\ Adelaide, South Australia \\ E-mail: ilke.onur@unisa.edu.au
}

\section{Frank Stähler}

Department of Economics, University of Tübingen, Tübingen, Germany and Department of Economics, University of Adelaide, Adelaide, Australia and Center for Economic Studies, The Ifo Institute (CESifo), Munich, Germany

E-mail: frank.staehler@uni-tuebingen.de 


\title{
The Scope of Auctions in the Presence of Downstream Interactions and Information Externalities
}

\author{
Onur A. Koska* \\ Ilke Onur ${ }^{\dagger}$ \\ Frank Stähler ${ }^{\ddagger}$
}

September 2016

\begin{abstract}
We scrutinize the scope of auctions for firm acquisitions in the presence of downstream interactions and information externalities. We show that no mechanism exists that allows an investor to acquire a low-cost firm under incomplete information: a separating auction implies adverse selection and relies substantially on commitment to allocation and transfer rules. A pooling auction serves as a commitment device against ex-post opportunistic behavior and alleviates adverse selection. It can earn the investor a higher expected payoff than a separating auction, even when consistency is required as to qualify for a sequential equilibrium.
\end{abstract}

Keywords: Takeover; Auction; Externality; Incomplete Information; Commitment

JEL Classification: D44; D82

*Corresponding author, Department of Economics, Middle East Technical University (METU), Çankaya 06800, Ankara, Turkey. Tel: +(90) 312210 3046. Fax: +(90) 312210 7964. Email: koska@metu.edu.tr

†School of Commerce, Division of Business, University of South Australia, Adelaide, South Australia 5001. Email: ilke.onur@unisa.edu.au

${ }^{\ddagger}$ Department of Economics, University of Tübingen, D-72074 Tübingen, Germany; CESifo, Germany; University of Adelaide, Australia. Email: frank.staehler@uni-tuebingen.de 


\section{Introduction}

After the extensive progress of auction theory in the last decades, it is a common view that private sales under incomplete information are in most cases strategically equivalent to a standard auction format, while the specific format has no bearing on the expected revenue under certain conditions as is shown by the Revenue Equivalence Theorem. Standard auction models, however, do not allow for any further interaction among bidders once the auction is over. Typically, in such models, auctions with symmetric bidders are efficient: the bidder with the highest valuation wins the auction; see Janssen and Karamychev (2009), Janssen and Moldovanu (2004), and Myerson (1981) $!^{1}$ Furthermore, auction theory assumes binding rules of the auction although manipulation of rules is frequently observed (e.g., shill bidding in Internet auctions, accepting subsequent offers after an auction closes in corporate acquisitions, or re-auctioning unsold items in real-estate sales) ${ }^{2}$ If ex-ante commitment to an allocation rule is not ex-post credible, the bidders anticipate some ex-post modification of the auction and adjust their bids accordingly. In such a case, the seller (or the buyer if it is a reverse auction $)^{3}$ mostly bears the cost, since the auction generates smaller rents; see Hoppe et al. (2006), Janssen and Karamychev (2010), and Jehiel and Moldovanu (2006).

Consequently, the auction literature has investigated the role of binding rules and further interactions among bidders separately. However, both are important in the context of firm acquisitions, and therefore we investigate commitment to auction rules and post-auction interactions at the same time. In particular, we consider a private (foreign) firm that wants to acquire one out of two target firms with private costs. $4^{4}$ The two firms quote acquisition prices in a (reverse) takeover auction, and compete by

\footnotetext{
${ }^{1}$ Procurement environments with incomplete information may generate different results. Focusing on procurement and modeling information asymmetries on the quality dimension, for example, Manelli and Vincent (1995) show that standard auction mechanisms are often inefficient, especially due to the adverse selection aspect of procurement environments. See, also, Klemperer (1999; 2004) and Krishna (2002) for reviews of the literature on auction theory.

${ }^{2}$ For more details and some anecdotal evidence, see McAdams and Schwarz (2006; 2007), Vartiainen (2013), and Skreta (2015).

${ }^{3}$ In reverse auctions (procurement auctions, subcontracting, etc.) a buyer asks potential sellers to quote prices for a particular contract.

${ }^{4}$ Mergers and acquisitions have been the driving force of international integration and have increased substantially, especially in the post-deregulation era of the 1990s (e.g., see Andrade et al., 2001). According to UNCTAD (2014), close to $35 \%$ of all global foreign direct investment took place as cross-border mergers and acquisitions (valued at US\$349bn in 2013). Also Boone and Mulherin (2007) show that auctions were employed in half of the takeovers of major U.S. firms in the 1990s. However, not all mergers and acquisitions are successful (see e.g., Gugler et al., 2003), indicating asymmetric information.
} 
quantities after the auction.5 The outcome of the auction may generate information externalities as the firms update their beliefs about their private cost information. In this framework, we show that there is no mechanism that allows the investor to acquire the low-cost firm. She is able to acquire the high-cost firm in a (separating equilibrium) reverse auction, but this has the cost of adverse selection. A second-price auction does not allow the acquired firm to appropriate a share of potential gains from acquisition, and thus earns the investor a higher expected payoff than a first-price auction. However, commitment to select the high-cost firm is crucial and may jeopardize both separating takeover procedures. The scope of a reverse auction that separates different types is very small without commitment due to the investor's potential opportunistic behavior in post-auction interactions. Alternatively, the investor can run a takeover auction in which she expects all target firms to quote the same price in a pooling equilibrium ${ }^{6}$ Our novel result is that a pooling takeover auction serves as a commitment device against ex-post opportunistic behavior, alleviates adverse selection, and can earn the investor a higher expected payoff than a separating auction. This result holds not only for a pooling takeover auction that qualifies for a weak perfect Bayesian equilibrium, but also when consistency is required as to qualify for a sequential equilibrium.

Our paper is mostly related to the following strands of the recent auction literature: (i) commitment in auctions, (ii) auctions with post-auction interactions, and (iii) auctions with externalities. Commitment issues in auctions have been scrutinized recently by several papers. McAdams and Schwarz (2007), for example, formally introduce the lack of commitment, such that the seller, after having observed the bids, cannot commit not to ask for another round of bids. Vartiainen (2013) allows for both the seller and the bidders not to commit to the auction rules, and he assumes that all actions are publicly observable. Skreta (2015) discusses an auction in which the seller can re-auction the good if it has not been sold. The seller in her model discounts the future, and thus the lack of commitment is costly for the seller. In these studies, an auction mechanism is followed by another auction-like mechanism, and the commitment problem arises when the good does not sell in the first round (or when there is scope for increasing rents by prolonging the auction). In our study, the lack of commitment, which may invalidate

\footnotetext{
${ }^{5}$ See Pagnozzi and Rosato (2016) for an alternative analysis of takeover auctions in which an entrant and some incumbent firms, first, compete in an auction to acquire a target firm, then compete by quantities on the product market. They also compare the takeover auction mechanism with bilateral negotiations. Their model, however, does not look at commitment to auction rules, nor does it consider asymmetric information.

${ }^{6}$ Throughout the paper, we refer to an auction with a separating equilibrium as a separating auction, and we refer to an auction with a pooling equilibrium as a pooling auction.
} 
the auction, is due to existence of post-auction oligopolistic competition that does not depend on the outcome of the auction.

We can also relate our study to the literature on auctions with resale (or rather, auctions followed by some post-auction interactions), although commitment to the auction rules has not been an issue in this strand of the literature. Studies on auctions with resale tend to focus on asymmetries among bidders resulting in inefficient allocations, and argue that there may be a motive for post-auction resale insofar as the outcome of the auction is potentially inefficient; see, among others, Gupta and Lebrun (1999), Haile (2003), and Hafalir and Krishna (2008; 2009). This literature finds that postauction resale (via ex-post bargaining) may generate efficiency, even though fear of revealing private information in the auction stage renders the allocation inefficient. In such auctions, existence of a monotonic equilibrium warrants that the losing bid (or valuations) should not be made public.7 In our study, however, disclosure of bids is inconsequential and the inefficient mechanism that separates different types is not the reason for post-auction interactions, but rather a result of post-auction oligopolistic competition.

In our study, there are both downstream interactions and informational and allocative interdependencies as in Jehiel and Moldovanu (2000), relating our study to the literature on auctions with externalities. Jehiel and Moldovanu (2000) focus on downstream externalities: they employ a second-price sealed-bid auction and model both the sale of a cost-reducing innovation to firms (which leads to negative externalities) and a merger between two out of three firms competing in the same industry (which leads to positive externalities). They show the existence of a separating equilibrium in the presence of negative externalities, and no separating equilibrium but pooling equilibria in the presence of positive externalities. In their model, only firms bidding in the auction are exposed to externalities, and, although the information structure is incomplete ex ante (at the auction stage), there is complete information ex post (at the product-market competition stage). In our study, however, all agents are exposed to information externalities and depend on characteristics that are not observable. More importantly, we relax their assumption that all private information is revealed after the auction, and we focus on the perfect Bayesian equilibrium concept.

We allow for the possibility that the prices quoted in the takeover auction may serve as signals that influence beliefs on the intensity of competition in the product market.

\footnotetext{
${ }^{7}$ See Krishna (2002, chapter 4) for a discussion on the impossibility of efficiency in a first-price auction with resale when all bids are made public.
} 
This approach is similar to Goeree (2003) and, more recently, to Ding et al. (2013). Goeree (2003) considers an auction setup in which bidders with incomplete information compete for a cost-reducing patent. All bidders, the winner and the losers, then compete in an aftermarket. He shows that bidders signal their private information via the winning bid, and this puts an upward bias on the equilibrium bidding strategies. In a different model, Ding et al. (2013) employ a similar signaling approach and compare different takeover auction mechanisms (e.g., first-price vs. second-price, cash vs. profit-sharing auction) in the presence of aftermarket Cournot competition. Another study that includes aftermarket competition in the analysis is one by Janssen and Karamychev (2010). They focus on auctioning of multiple licenses and on the winning firms that compete in the aftermarket. They show that the auction mechanism does not always choose the most cost-efficient firms. Our main contribution, relative to the articles mentioned above, is that we look at the scope for (credible) commitment to the rules of the auction in the presence of downstream interactions and information externalities.

The rest of the paper is organized as follows. Section 2 introduces the Cournot duopoly model under incomplete information, shows that no mechanism that allows an investor to acquire the low-cost firm exists, and introduces two commitment conditions that are crucial for the separating (reverse) auctions. Section 3 solves the model for a symmetric, fully-separating equilibrium in strictly decreasing bidding strategies for a first-price and a second-price takeover auction and discusses their revenue implications as well as their reliance on the commitment conditions. Section 4 develops two different pooling takeover auctions and compares the investor's expected payoffs with those in separating takeover auctions. Finally, Section 5 concludes. For convenience, we have relegated most of the proofs and technical details to the Appendix.

\section{The model}

In what follows, we consider a game that has five stages as outlined by Table 1 . There are two firms whose production costs are private information (see stage 1) and one investor who designs an auction for firm acquisition (stage 2), which is followed by acquisition prices quoted by the potential target firms (stage 3) and then by an acquisition decision made by the investor based on the quoted prices (stage 4). $]^{8}$ In the

\footnotetext{
${ }^{8}$ We set up the model such that the investor is not allowed to acquire both firms. The reason is that local competition authorities would not permit the foreign firm to gain monopoly power.
} 
last stage, the market is served by two firms. Consumers in this market have quasilinear preferences such that the inverse demand function is given by $p=a-\left(q_{i}+q_{j}\right)$, $i \neq j$ and $i, j=\{1,2\}$, where $p$ denotes the equilibrium price, and $q_{i}$ and $q_{j}$ are the respective outputs of the two firms producing homogeneous goods. Both firms draw their marginal production cost (independently) from the uniform distribution $F(c)=c$; hence, the marginal costs are distributed over the support $[0,1]$.

Table 1: Game structure

Stage $I:$
$\begin{gathered}\text { Nature selects the marginal cost } c_{i} \in[0,1] \text { of both target firms. } \\ \text { Each target firm privately learns its marginal cost } c_{i} .\end{gathered}$
Stage $I I:$
The investor announces an auction design
that specifies an allocation rule and a transfer scheme.
Stage III:
Each target firm quotes a unilaterally binding acquisition price.
Stage $I V$ :
The investor accepts one price or rejects both prices.
The investor accepts one price, she enters the market by firm acquisition.
If the investor rejects both prices, she stays out of the market.
Stage $V:$
Firms that are in the market compete by quantities.

Without any acquisition, the two firms would compete in a Cournot duopoly and would produce at the level maximizing their expected profits $\Pi_{i}=\left(a-q_{i}-E_{i}\left(q_{j}\right)-c_{i}\right) q_{i}$, $i \neq j$ and $i, j=\{1,2\}$, where $E_{i}\left(q_{j}\right)$ is firm $i$ 's expectation of firm $j$ 's output. Firms do not know each other's marginal production cost, but they can correctly anticipate each other's optimal behavior. We can derive the optimal outputs as a function of firm-specific marginal production costs and expected costs:

$$
q_{i}=\frac{2 a-E_{j}\left(c_{i}\right)+2 E_{i}\left(c_{j}\right)-3 c_{i}}{6}, \quad i \neq j \text { and } i, j=\{1,2\}
$$

We will assume throughout the paper that $a>2$ which guarantees that outputs are positive even if $E_{j}\left(c_{i}\right)=c_{i}=1$ and $E_{i}\left(c_{j}\right)=0, i \neq j$. In equation (1), $c_{i}$ is firm $i$ 's realized marginal production cost, and $E_{i}\left(c_{j}\right)$ is firm $i$ 's expectation of firm $j$ 's marginal production cost. Firms update their beliefs on each other's marginal production cost with any relevant information that is revealed before they make their output decisions. Without acquisition and if no further information is revealed until the two firms make their output decisions, $E_{i}\left(c_{j}\right)=E_{j}\left(c_{i}\right)=1 / 2$. From equation (1), we can derive the 
expected profits:

$$
\pi\left(c_{i}\right)=\left(\frac{2 a-E_{j}\left(c_{i}\right)+2 E_{i}\left(c_{j}\right)-3 c_{i}}{6}\right)^{2}, \quad i \neq j \text { and } i, j=\{1,2\} .
$$

Equation (2) shows that a firm's expected profit is positively related to its expectation of its rival's cost, and is negatively related to the rival firm's expectation of its own cost. Any information that reveals, before the firms make their output decisions, that firm $j$ is a low-cost firm leads firm $i$ to update its beliefs, such that $E_{i}\left(c_{j}\right)$ becomes smaller, and hence decreases firm $i$ 's expected profits and increases firm $j$ 's expected profits, ceteris paribus.

The acquiring firm is an investor who considers the acquisition of one of the two target firms to enter the market. The investor may realize two different forms of acquisition benefits: (i) access to technologies, management skills, intangible assets etc., and (ii) combining its own (complementary) assets with those of the acquired firm for competition in the acquired firm's market. The first benefit is fixed and independent of the cost realization of the acquired firm, whereas the second benefit depends on the acquired firm's cost realization. If the investor acquires a firm, the acquired firm's marginal cost will decline to $\gamma c_{i}, i=\{1,2\}$, where $\gamma \in[0,1]$ is an (exogenously given) inverse measure of the cost-saving effect of the acquisition and is common knowledge. We can consider $\gamma$ as the investor's contribution to the ex-post productivity of the acquired firm: combining complementary assets of the investor and the acquired firm generates efficiency gains. Therefore, $\gamma=0$ implies that the investor's assets are substantially efficient, dominating the acquired firm's assets: the investor successfully carries over her technology to the acquired firm. Similarly, $\gamma=1$ implies that the acquisition of a firm generates no efficiency gains: ${ }^{9}$ the acquired firm's technology is used.

Let $v^{i}\left(c_{i}, c_{j}\right), i \neq j$ and $i, j=\{1,2\}$, denote the investor's aggregate operating profit after having acquired a target firm of cost-type $c_{i}$ and competing against a firm of type $c_{j}$. The superscript $i$ represents the firm that is acquired by the investor. The investor's ex-post aggregate payoff (excluding the cost of acquisition) consists of the fixed benefit

\footnotetext{
${ }^{9}$ Efficiency gains play an important role in the profitability of mergers and acquisitions: firms may benefit from a merger, provided sufficient efficiency gains are generated as in Perry and Porter (1985). Without efficiency gains, firms may not benefit from a merger if they compete in a market of strategic substitutes in the sense of Bulow et al. (1985) due to the merger paradox; see, for example, Salant et al. (1983), and Farrell and Shapiro (1990). Convex demand (Hennessy, 2000), product differentiation (Lommerud and Sorgard, 1997) and competition in a market of strategic complements (Deneckere and Davidson, 1985) can overcome the merger paradox. The merger paradox does not apply here as the investor stays out of the market and earns zero profit if no acquisition takes place.
} 
$\Gamma$ and the operating profit $v^{i}\left(c_{i}, c_{j}\right)$, and is equal to

$$
\Gamma+v^{i}\left(c_{i}, c_{j}\right) \text { where } v^{i}\left(c_{i}, c_{j}\right)=\left(\frac{2 a-E_{j}\left(c_{i}\right)+2 E_{i}\left(c_{j}\right)-3 \gamma c_{i}}{6}\right)^{2} .
$$

Since we are not interested in the role of the investor's participation constraint in this paper, we assume that the fixed benefit $\Gamma$ is sufficiently large and makes any firm acquisition worthwhile. This fixed benefit could also be adjusted by the inclusion of other entry options (e.g., greenfield investment). Our results would remain qualitatively the same, if the investor had to choose simultaneously between the acquisition of a local firm and greenfield investment 10 Empirical evidence suggests that such decisions are indeed made simultaneously, especially given a long lead time that greenfield investments generally require; see, for example, Raff et al. (2012).

Which type of firm should be targeted by the investor? Suppose that the investor learns the cost types such that $c_{i}<c_{j}, i \neq j$ and $i, j=\{1,2\}$. From an ex-post perspective, it is obvious from equation (3) that

$$
v^{i}\left(c_{i}, c_{j}\right)-v^{j}\left(c_{i}, c_{j}\right)=\left(\frac{2 a-4 \gamma c_{i}+2 c_{j}}{6}\right)^{2}-\left(\frac{2 a-4 \gamma c_{j}+2 c_{i}}{6}\right)^{2}>0,
$$

for any $c_{i}<c_{j}, i \neq j$ and $i, j=\{1,2\}$. Consequently, if the cost of acquiring either firm (the acquisition prices) were the same, and if the investor were free to choose any target firm, she would always select the low-cost firm. We will see later that this incentive may lead to serious complications if ex-ante commitment to select a certain type is not possible. Not surprisingly, we also find a clear ex-ante preference of the investor under asymmetric information, but we have to conclude that this is not a viable option.

Proposition 1 The investor's expected operating profit of acquiring the low-cost firm and competing against the high-cost firm is larger than the expected operating profit of acquiring the high-cost firm and competing against the low-cost firm. However, there is no implementable mechanism that allows the investor to select the low-cost firm under asymmetric information.

Proof: See Appendix A.1.

\footnotetext{
${ }^{10}$ Scrutinizing the optimal entry mode when different options for foreign market entry are available is beyond the scope of this study; see Koska (2016) for a model that employs an ascending takeover auction in the case of complete information, and a second-price, sealed-bid, takeover auction in the case of incomplete information, and that looks at an investor's choice between firm acquisition and greenfield investment.
} 
The reason is that the compensation for a low-cost firm should increase with its high productivity, but this allows the high-cost firm to mimic the low-cost firm without any cost. Proposition 1 shows that any separating equilibrium must imply that the investor acquires the high-cost firm, and consequently, the best a separating auction setup can achieve is to target the high-cost firm.

We will now scrutinize the scope of separating and pooling auctions, both to be explained in detail in the subsequent sections. In any separating auction, if it is a feasible design, bidders will truthfully reveal their type, and the scope of separating auctions will crucially depend on

Condition 1 (Allocation rule) If the investor decides to acquire a firm, she will commit to acquire the firm quoting the lowest acquisition price.

In a pooling auction, both prices will coincide so Condition 1 is immaterial in this type of auctions, as the investor does not learn the type and will select each target with equal ex-ante probability. If Condition 1 holds, and the auction setup is such that the winner receives his quoted price (that is, if it is a first-price reverse auction), no further commitment is necessary. However, if the winner receives the (higher) price quoted by the loser, we will also need

Condition 2 (Transfer scheme in a second-price reverse auction) If the investor decides to acquire a firm, she will commit to compensate the firm quoting a lower price by the higher acquisition price quoted by the other firm.

It should be clear that Condition 2 is subordinate to Condition 1 , meaning that Condition 2 cannot be met without Condition 1. The investor cannot credibly commit to a transfer scheme which implies a second-price reverse auction when she is not able to commit to select the lower bid. Therefore, it is already obvious that any second-price reverse auction will require more commitment than a first-price reverse auction.

\section{The scope of separating auctions}

In this section, we consider two different sealed-bid auction formats, the first-price reverse auction and the second-price reverse auction. Both auction setups, if feasible, lead to cost revelation, and the "quality of a match" is determined by the size of 
the ex-post marginal cost and is the potential target firms' private information 11 The acquisition prices quoted in the auction determine the investor's market entry cost, and are not disclosed after the auction, 12

We start with the first-price reverse auction in which, after acquisition prices have been quoted, the investor acquires one of the two target firms. In the last stage, the investor and the non-acquired firm update their beliefs on each other's productivity, and compete in a Cournot duopoly. Suppose that Condition 1 holds, and let $\phi_{i}$ denote firm $i$ 's quoted price that is monotonic and strictly increasing in firm $i$ 's productivity (i.e., strictly decreasing in its marginal production cost), an assumption that we have to confirm later. The higher is the firm's marginal cost, the smaller is the quoted price. We find:

Proposition 2 If Condition 1 is fulfilled, the first-price reverse auction has a symmetric, fully-separating equilibrium in strictly decreasing bidding strategies. In equilibrium, firm $i$ quotes

$$
\begin{aligned}
\phi^{*}\left(c_{i}, \gamma\right) & \equiv \phi^{*}\left(c_{i}, \gamma=0\right)+\gamma \Delta\left(c_{i}, \gamma\right), \text { where } \\
\phi^{*}\left(c_{i}, \gamma=0\right) & =\left(\frac{2 a^{2}+2 a+4 c_{i}^{2}-5 a c_{i}-2 c_{i}}{18}\right) \text { and } \\
\Delta\left(c_{i}, \gamma\right) & =\left(\frac{2+4 a c_{i}-6 c_{i}^{2}-\left(1-c_{i}-c_{i}^{2}\right) \gamma}{36}\right) .
\end{aligned}
$$

Proof: See Appendix A.2.

The following remarks are in order. Provided Condition 1 is fulfilled, it is individually rational for both firms to quote prices that are a function of their private information (marginal costs). The profit-maximizing strategy is thus to quote a price that signals true productivity. Therefore, the outcome of the auction reveals valuable information that will affect future interactions on the product market.

Proposition 2 shows that in a larger market ( $a$ is bigger), firms quote higher prices in equilibrium, as they expect a higher profit: it will be, ceteris paribus, more costly to enter a larger market by acquiring a firm. By the same token, for any given market size $a>2$ and cost-saving effect $\gamma \in[0,1]$, it will be more costly to acquire a lower-cost

\footnotetext{
${ }^{11}$ Formally, we consider a perfect Bayesian equilibrium. We do not consider a potential repetition of an auction as in Skreta (2015). A well-known complication in these setups is the ratchet effect; see Freixas et al. (1985), and Laffont and Tirole (1988).

${ }^{12}$ Our results would not change qualitatively if bids were (honestly) disclosed. However, we find this setup more compelling, also because the investor would always claim that the winning firm was just as productive as the losing firm unless she could credibly commit to reveal the bids truthfully.
} 
firm, such that $\partial \phi_{i}^{*}\left(c_{i}, \gamma\right) / \partial c_{i}<0$ : if it competes against the investor, a lower marginal production cost secures a larger market share and thus a higher profit in expected terms. Moreover, the quoted prices increase with a decreasing cost-saving effect, such that $\partial \phi_{i}^{*}\left(c_{i}, \gamma\right) / \partial \gamma>0$ for all $a>2$ and $c_{i}, \gamma \in[0,1]$. Firms quote relatively low prices, $\phi_{i}^{*}\left(c_{i}, \gamma=0\right)$, when their market share will be small when competing against a strong investor (that is, when $\gamma=0$ ). As the cost-saving effect gets smaller (such that $\gamma \neq 0$ increases), firms anticipate that the acquired firm will produce with a larger marginal cost, which leads them to expect a larger market share and larger expected profits when competing against the investor. Therefore, they quote higher prices, $\phi_{i}^{*}\left(c_{i}, \gamma>0\right)$ (see equation (5), given by Proposition 2), such that they compensate for the increase in their outside profits.

Given equation (5), we are now able to compute the investor's ex-ante expected payoff. Let $c_{(1)}$ and $c_{(2)}$ denote the signals that are rearranged in ascending order: $c_{(1)}$ is the lowest-cost signal, and $c_{(2)}$ is the highest-cost signal, such that $c_{(1)}<c_{(2)}$. Given the uniform distribution $F(c)=c$, we can write the highest-order statistics, denoted by $F_{1}(c)$, such that $F_{1}(c)=F(c)^{2}=c^{2}$. The investor's ex-ante expected profit from a firstprice reverse takeover auction (which follows Condition 1), denoted by $\hat{V}^{a}$, is equal to

$$
\begin{aligned}
\hat{V}^{a} & =\int_{0}^{1}\left(\int_{0}^{c_{(2)}} v^{(2)}\left(c_{(1)}, c_{(2)}\right) d F\left(c_{(1)}\right)-\phi^{*}\left(c_{(2)}\right)\right) d F_{1}\left(c_{(2)}\right)+\Gamma \\
& =\int_{0}^{1} 2 c_{(2)}\left(\int_{0}^{c_{(2)}} \frac{v^{(2)}\left(c_{(1)}, c_{(2)}\right)}{c_{(2)}} d c_{(1)}-\phi^{*}\left(c_{(2)}\right)\right) d c_{(2)}+\Gamma \\
& =\frac{64 a(2-5 \gamma)+\gamma(181 \gamma-72)-16}{864}+\Gamma,
\end{aligned}
$$

where $v^{(2)}\left(c_{(1)}, c_{(2)}\right)$, derived from equation (3), denotes the investor's operating profit after having acquired the high-cost firm, and $\phi^{*}\left(c_{(2)}\right)$ is derived from equation (5). Note carefully that the variable gains from the acquisition of a firm can be negative: the auction includes the possibility to acquire a lemon and to compete against a strong (high-productivity) rival.

We now show that a lack of commitment may jeopardize the whole acquisition process as the takeover procedure via such a separating auction is prone to ex-post opportunistic behavior exploiting information externalities. Without commitment (Condition 1), the investor may find it profitable ex post to acquire the low-cost firm, as we could already see from equation (4). This incentive depends on the market size, the size of the ex-post marginal production cost, and on the difference in quoted acquisition prices. We will show that the investor will want to continue to acquire the high-cost firm only in a sufficiently large market, especially when there is sufficiently large cost-saving. 
Suppose that both target firms continue to believe that the high-cost firm will be selected, but the investor were free to select any firm for acquisition, and she would pick firm $i$. Let $V^{i}\left(c_{i}, c_{j}\right)$ denote the investor's ex-post profit after having acquired firm $i$ and when competing against firm $j$ :

$$
V^{i}\left(c_{i}, c_{j}\right)=\left(\frac{2 a-\gamma\left(1+c_{j}\right) / 2+2 c_{j}-3 \gamma c_{i}}{6}\right)^{2}-\phi^{*}\left(c_{i}\right)+\Gamma ; \quad i \neq j \in\{1,2\} .
$$

The first expression of the RHS is derived from equation (3) and represents the investor's operating profit after having acquired firm $i$, where $\gamma\left(1+c_{j}\right) / 2$ corresponds to $E_{j}\left(c_{i}\right)$ in equation (3): this is the non-acquired firm's ex-post expectation of the acquired firm's marginal cost. The investor's market entry cost, which is equivalent to the acquired firm's quoted price, $\phi^{*}\left(c_{i}\right)$, is given by equation (5) (Proposition 2), and $\Gamma$ is the fixed benefit. The investor, after having received the quoted prices, correctly anticipates the rival's (the non-acquired firm's) realized marginal production cost from bidding behavior: $c_{j}$ in equation (7) corresponds to $E_{i}\left(c_{j}\right)$ in equation (3). In contrast, the non-acquired firm $j$, learning only that the other firm has been acquired, updates its belief about the size of the ex-post marginal cost such that it believes to be the low-cost firm and consequently $E_{j}\left(c_{i}\right)=\gamma\left(1+c_{j}\right) / 2$. It is clear from equations (5) and (7) that (i) higher cost-saving (lower $\gamma$ ) leads not only to higher operating profits, but also smaller market entry costs; (ii) the impact of cost-saving on the investor's profit is accentuated in a larger market; and (iii) acquiring a high-cost firm - larger $c_{i}$ in equation (7) - increases the size of the ex-post marginal cost (and so decreases the investor's operating profits), while decreasing the investor's market entry costs. We are now ready to scrutinize the role of Condition 1. We define:

Definition 1 A reverse takeover auction is self-enforcing, if it is optimal ex post for the investor to select the firm that quotes the lower acquisition price, given that both firms follow the bidding strategy, given by Proposition 2.

A separating first-price takeover auction will be self-enforcing only if the investor's profit $V^{i}\left(c_{i}, c_{j}\right), i \neq j \in\{1,2\}$, given by equation (7), in the case of acquiring the firm quoting a lower price is larger than the profit she could have earned by acquiring the other firm. So, when does a separating first-price takeover auction work without Condition 11? We find:

Proposition 3 For any given market size a $>2$ and firms' cost draws $c_{i}, c_{j} \in[0,1], i$, $j=\{1,2\}$, and for the threshold of cost-saving, denoted by $\widetilde{\gamma} \simeq 0.32$ :

1. If $\gamma \geq \widetilde{\gamma}$, the separating takeover auction is never self-enforcing. 
2. If $\gamma<\widetilde{\gamma}$,

(a) the separating takeover auction can be self-enforcing only for some values of $c_{i}, c_{j}$ if $a<10$ and/or $\gamma$ is sufficiently large;

(b) the separating takeover auction is self-enforcing for all $c_{i}, c_{j} \in[0,1]$ if a $>10$ and $\gamma$ is sufficiently small.

Proof: See Appendix A.3.

Proposition 3 demonstrates that the investor will always want to select the high-cost firm if and only if cost-saving is substantial ( $\gamma$ is sufficiently small) and the market is sufficiently large. The intuition is as follows. If cost-saving is sufficiently large, the size of the ex-post marginal cost $\left(\gamma c_{i}\right)$ will be sufficiently low (even after having acquired the high-cost firm). A sufficiently low ex-post marginal cost guarantees the investor a large market share and a small one for the non-acquired firm so that the investor's market entry cost is reduced significantly. In a sufficiently large market, these effects are accentuated, such that the decrease in market entry costs dominates the market share effect. If, however, the market is sufficiently small, such that $a<10$, the target firms will anticipate that the investor's incentive to reduce the rival's market share dominates her incentive to decrease the market entry cost, irrespective of cost-saving. Thus, Proposition 3 suggests that both a sufficiently large market and sufficiently high cost-saving are necessary in order to ensure the firms that a separating first-price takeover auction can be run without Condition 1 .

We illustrate these results in Figure 1, which shows the set of parameter values of market size $(a)$ and cost-saving $(\gamma<\widetilde{\gamma})$ for which the investor's commitment (i) is not self-enforcing for any given $c_{i}, c_{j} \in[0,1]$ in Region I, (ii) may or may not be selfenforcing for a given $c_{i}$ and $c_{j}$ in Region II, or (iii) is self-enforcing for any given $c_{i}$, $c_{j} \in[0,1]$ in Region III. Region III is the only region in Figure 1 where the target firms can be sure that the investor will have no incentive to select the low-cost firm without binding commitment. In this region, both the market size is sufficiently large and cost-saving is sufficiently high. In Regions I and II, the target firms anticipate that a separating takeover auction is not self-enforcing. In Region II, for example, the investor wants to acquire the lower-cost firm (which quotes a higher price) if the average industry marginal cost before the acquisition of a firm takes place, $C / 2=\left(\sum_{i=1}^{2} c_{i}\right) / 2$, is sufficiently large (for details, see Appendix A.3). Although a separating takeover auction can be self-enforcing if $C$ is sufficiently small, the firms do not know the average industry marginal cost at the time of the auction. If the target firms anticipate that 


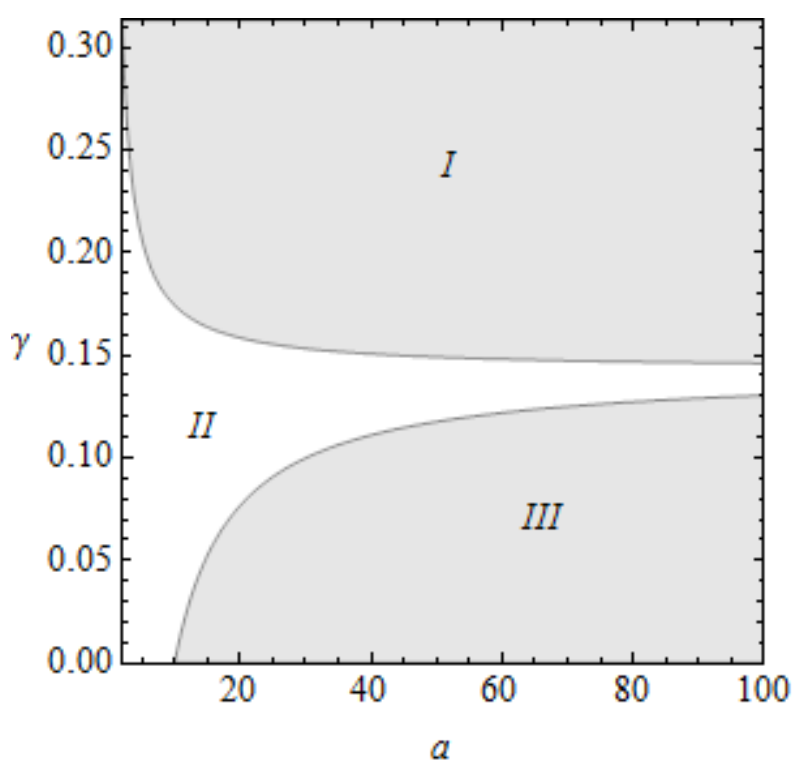

Figure 1: The scope of self-enforcing auctions

there is a conflict between the investor's ex-ante commitment to a particular allocation mechanism and her objective of maximizing ex-post profits after having seen the quoted prices, they will no longer follow the bidding strategy, given by Proposition 2. An optimal response for all types of firms is, then, to quote the highest price that the lowest-cost firm would have quoted, making their bidding behavior inconsistent with the beliefs of the investor. Consequently, the takeover procedure is no longer strategically equivalent to a first-price reverse auction and does not lead to symmetric and fullyseparating equilibrium in strictly decreasing bidding strategies. In such a situation, a separating equilibrium cannot exist without Condition 1.

We next consider the other class of sealed-bid auctions, a second-price (separating) takeover auction, in which the winner who quotes the lower acquisition price gets the higher acquisition price quoted by the other firm. Since the quoted prices are not disclosed, this setup obviously warrants additional commitment given by Condition 2 , the investor must be able to commit to truthfully compensating the winner by the (higher) acquisition price quoted by the loser. If this commitment fails, we will be back to the setup that we have already scrutinized above. The reason is simple. The investor would have an incentive to claim that the rival's price was just a small $\epsilon>0$ above the price quoted by the winner so as to decrease the cost of acquisition and increase her profits as much as possible. Since Condition 2 is subordinate to Condition 1 , the alternative setup is feasible only if both conditions hold and we may confine the analysis 
to the payoff implications for the investor: would the investor do better in a different separating auction if she could commit credibly to both the allocation rule and the transfer scheme? Suppose that both Condition 1 and Condition 2 hold and let $\phi^{s *}$ denote the quoted prices in equilibrium where the superscript $s$ denotes the secondprice (reverse) takeover auction. It is straightforward to show that each firm has a weakly dominant strategy of quoting its own valuation of acquisition, which is the minimum payoff that yields a nonnegative surplus.13 That is, in our context, each target firm will quote the expected profit of competing against the investor such that

$$
\phi_{i}^{s *}=\left(\frac{2 a+\gamma-(4-\gamma) c_{i}}{6}\right)^{2} .
$$

Equation (8) is derived from equation (2), where $E_{j}\left(c_{i}\right)$ - the investor's expectation of the marginal production cost of firm $i$ - is replaced by $c_{i}$, because the investor, having observed the quoted prices, can correctly anticipate the realization of the firms' marginal production costs. Firm $i$, by contrast, will only know that the investor acquires the rival firm because the rival's marginal cost is higher, enabling the rival to quote a lower price. Therefore, $E_{i}\left(c_{j}\right)$ in equation (2) - firm $i$ 's expectation of the acquired firm's marginal cost - is replaced by $\gamma\left(1+c_{i}\right) / 2$.

Following equation (6), we can compute the investor's ex-ante expected payoff from a second-price takeover auction, denoted by $\hat{V}^{s}$, as

$$
\begin{aligned}
\hat{V}^{s} & =\int_{0}^{1}\left(\int_{0}^{c_{(2)}}\left(v^{(2)}\left(c_{(1)}, c_{(2)}\right)-\phi^{s *}\left(c_{(1)}\right)\right) d F\left(c_{(1)}\right)\right) d F_{1}\left(c_{(2)}\right)+\Gamma \\
& =\int_{0}^{1} 2 c_{(2)}\left(\int_{0}^{c_{(2)}} \frac{\left(v^{(2)}\left(c_{(1)}, c_{(2)}\right)-\phi^{s *}\left(c_{(1)}\right)\right)}{c_{(2)}} d c_{(1)}\right) d c_{(2)}+\Gamma \\
& =\frac{64 a(1-2 \gamma)+47 \gamma^{2}-16}{288}+\Gamma,
\end{aligned}
$$

where $\phi^{s *}$ is given by equation (8), and $v^{(2)}\left(c_{(1)}, c_{(2)}\right)$, derived from equation (3), is the investor's operating profit after having acquired the high-cost firm and $c_{(1)}$ and $c_{(2)}$ are the cost signals where $c_{(1)}<c_{(2)}$. We find:

Proposition 4 A second-price reverse takeover auction yields a higher expected payoff for the investor than a first-price reverse takeover auction if $\gamma<1$. The two separating takeover auctions are revenue equivalent when $\gamma=1$.

Proof: See Appendix A.4.

${ }^{13}$ See, for example, Krishna (2002) for a sketch of the general proof. 
Why does the second-price auction do better in terms of expected investor payoffs? Note carefully that the investor's operating profit after having acquired the high-cost firm is the same across the two separating takeover auctions. The main difference is the ex-ante expected cost of acquisition. In the first-price auction, the optimal bids balance the risk of not winning the auction and competing against a strong rival against winning the auction and getting a share of the productivity gains. Hence, the first-price auction allows the winning target firm to appropriate a share of the potential gains, but the second-price auction does not. Firms bid their outside options and the winner gets the loser's outside option. Therefore, the second-price auction allows the investor to appropriate all productivity gains. Given this background, it is not surprising that revenue equivalence holds only if there are no productivity gains, that is, if $\gamma=1$.

\section{The scope of pooling auctions}

An alternative auction setup is given if the investor expects both firms to quote the same acquisition price, irrespective of their cost-types. In order to scrutinize this possibility, we have to be more explicit about the investor's belief structure. In standard auctions, the belief structure does not play a critical role: bidders reveal their types, but this is inconsequential. In the previous sections, however, the belief structure has been consequential: the quoted prices in the takeover auction and the takeover itself convey information, and the firms update their beliefs about their future rival. Furthermore, the investor may want to accept the higher acquisition price, making the separating auction setup vulnerable to ex-post opportunistic behavior.

If, however, an equilibrium exists in the pooling auction, then the investor, in equilibrium, will not be able to update her beliefs but will continue to use her priors to evaluate the expected outcomes as all types will quote the same acquisition price. While there is no room for a pooling equilibrium in standard auctions, we show that it plays an important role in our setup. In this sense, a pooling auction setup serves as a commitment device to avoid ex-post opportunistic behavior ${ }^{14}$ A delicate issue in pooling equilibria is the specification of out-of-equilibrium beliefs that will support the equilibrium. In this section, we will consider two concepts, the weak perfect Bayesian equilibrium (weak PBE) concept and the sequential equilibrium (SE) concept.

\footnotetext{
${ }^{14} \mathrm{~A}$ pooling auction is strategically equivalent to a game in which an investor (i) can make simultaneous take-it-or-leave-it offers to both firms and (ii) has a certain belief structure on types depending on their unilateral acceptance. This should not be confused with take-it-or-leave-it acquisition offers to target firms that are desinged to separate types (see Koska and Stähler, 2014).
} 
We start with the weak PBE for which we assume that the investor is able to convince both target firms that she will believe that any firm not quoting the (common) acquisition price she has in mind will be thought of being the highest-cost firm. The idea is that the investor sets up an auction and, prior to running it, communicates to the target firms which offer she will expect and accept, and that any firm deviating from this will be considered as the highest-cost firm.

In particular, assume that a pooling equilibrium exists in which both firms quote an acquisition price $\Phi^{*}$. The investor forms beliefs as follows: (i) if any firm quotes $\Phi^{*}$, the investor believes that this firm's marginal production cost is uniformly distributed between 0 and 1; (ii) if any firm quotes an acquisition price $\Phi \neq \Phi^{*}$, the investor believes that this firm has the highest marginal cost of 1 . Let the investor's beliefs on the expected cost of firm $i$ as a function of firm $i$ 's bid $\Phi_{i}$ be denoted by $\mu_{i}\left(\Phi_{i}\right)$, $i=\{1,2\}$. Then, this belief structure specifies

$$
\mu_{i}\left(\Phi_{i}=\Phi^{*}\right)=\frac{1}{2} \quad \text { and } \quad \mu_{i}\left(\Phi_{i} \neq \Phi^{*}\right)=1 .
$$

If a pooling equilibrium exists, the investor's expected profit from firm acquisition via a pooling auction, denoted by $\hat{V}^{p}\left(\Phi^{*}\right)$ where the superscript $p$ stands for pooling, is given by

$$
\begin{aligned}
\hat{V}^{p}\left(\Phi^{*}\right) & =\int_{0}^{1}\left(\frac{2 a-\gamma / 2+1-3 \gamma c}{6}\right)^{2} d c-\Phi^{*}+\Gamma \\
& =\frac{(2 a+1-2 \gamma)^{2}}{36}+\frac{\gamma^{2}}{48}-\Phi^{*}+\Gamma .
\end{aligned}
$$

Both target firms quote the same price $\Phi^{*}$. Therefore, the investor randomizes when selecting one of the target firms, which look identical to her. Each target firm's expected profit from a pooling auction, denoted $\hat{\pi}^{p}\left(c_{i}\right), i=\{1,2\}$, is thus given by

$$
\hat{\pi}^{p}\left(c_{i}\right)=\frac{1}{2} \Phi^{*}+\frac{1}{2}\left(\frac{2 a-1 / 2+\gamma-3 c_{i}}{6}\right)^{2} .
$$

Any weak PBE supported by this belief structure has to fulfill the condition that no firm has an incentive to quote a different acquisition price. If any firm quotes a higher price than $\Phi^{*}$, the investor will never select this firm, but will update her beliefs, such that after the acquisition of the other firm, she will have received the good news that the rival has the highest cost. This specifies a lower bound for the acquisition price: if $\Phi^{*}$ is too low, a target firm might find it more profitable not to quote it and lose the auction even if this leads the investor to believe that the firm has the highest cost. If, however, any firm quotes a lower acquisition price than $\Phi^{*}$, this lower price will 
be accepted by the investor only if it undercuts $\Phi^{*}$ substantially: the investor believes that the defecting firm is of highest cost-type, which increases the expected operating profit from the acquisition of the rival firm and decreases the operating profit from the acquisition of the defecting firm. This defection option puts an upper bound on $\Phi^{*}$ : if $\Phi^{*}$ is very large, it is relatively costless to undercut the candidate pooling acquisition price. Appendix A.5 has the details of the defection options and proves that

Proposition 5 Weak PBEs exist: the investor forms beliefs according to equation (10), and each target firm quotes the same acquisition price $\Phi^{*} \in[\underline{\Phi}, \bar{\Phi}]$ where

$$
\begin{aligned}
& \bar{\Phi}=\frac{(2 a+2-2 \gamma)^{2}}{18}+\frac{\gamma^{2}}{24}-\frac{(2 a-7 \gamma / 2+1)^{2}}{18}+\frac{(2 a-7 / 2+\gamma)^{2}}{36}, \\
& \underline{\Phi}=\frac{(2 a-1+\gamma)^{2}}{18}-\frac{(2 a-1 / 2+\gamma)^{2}}{36} .
\end{aligned}
$$

Proof: See Appendix A.5.

Proposition 5 demonstrates a range of weak PBEs. Of course, the best one for the investor would be to convince both firms that she believes that both firms quote the lowest bid. Substituting $\Phi^{*}=\underline{\Phi}$ into equation (11) gives the investor's maximum expected payoff in the weak PBE pooling auction:

$$
\begin{aligned}
\hat{V}^{p}\left(\Phi^{*}=\underline{\Phi}\right) & =\frac{(2 a+1-2 \gamma)^{2}}{36}+\frac{\gamma^{2}}{48}-\underline{\Phi}+\Gamma \\
& =\frac{1}{144}(8 a(5-6 \gamma)+(1+3 \gamma)(5 \gamma-3))+\Gamma
\end{aligned}
$$

How does the outcome of the pooling auction compare to that of the separating auction? We find:

Proposition 6 The best weak PBE has a higher expected payoff for the investor than both separating (auction) equilibria.

Proof: See Appendix A.6.

This is a strong result. We find that the investor can always do better with a weak PBE pooling auction. On the one hand, this auction allows her to commit not to exploit information revealed during the auction. On the other hand, any separating takeover auction can only be run such that the investor will select the high-cost firm, but the pooling auction alleviates adverse selection. With a pooling auction in which the target firms are expected to quote identical acquisition prices, the investor will have a chance to acquire the more profitable (low-cost) target firm. Proposition 6 also shows that 
there is even no revenue equivalence when $\gamma=0$, that is, when the investor will be able to produce with the least (zero) costs.

Why are revenues in the weak PBE auction strictly larger? In any separating auction, adverse selection decreases the investor's expected payoff because (i) it leads to a smaller decrease in marginal costs, and (ii) it implies that the rival will be a tough one. When $\gamma=0$, the first effect disappears, but the second effect is still there. We can show that the (best) weak PBE implies an acquisition price that is always smaller than the price for the highest-cost firm in a first-price auction. Employing a separating auction and thus paying more for firm acquisition enables the investor to learn the future rival's cost, but the news can be good or bad. On average, the learning gain is smaller than the learning cost even if this learning cost, that is, the difference between the first-price auction acquisition price and the (best) weak PBE price, is smallest for $c=1$ and $\gamma=0$. The key for understanding revenue dominance of the (best) weak PBE is the logic of the two bounds and the associated belief structure. The lower bound is derived such that the candidate equilibrium bid should not be too low that the least-cost firm is better off by quoting a higher price and by being treated as the highest-cost firm. Similarly, the upper bound is derived such that the candidate equilibrium bid should not be too high that the highest-cost firm undercuts the bid successfully so as to be picked despite being regarded as the highest-cost firm. The difference between the upper bound and the lower bound is strictly positive, even for $\gamma=0$, because underbidding leads the investor to believe that the firm is of the highest-cost and the expected profit of acquiring the other firm increases.

While the belief structure in equation 10 supports a weak PBE, it will not allow any firm to deviate marginally from the predicted strategy. We now consider the scope of a sequential equilibrium (SE) in the sense of Kreps and Wilson (1982) in this setup. The SE warrants that the equilibrium strategy is consistent such that it can be represented as the limit of a sequence of purely mixed strategies and beliefs where the beliefs are formed according to Bayes' Rule. The weak PBE does not qualify for an SE as it has a knife-edge property and cannot accommodate any sequence of strategies and beliefs converging to the equilibrium. The belief structure in a pooling auction that is an SE is given by

$$
\mu_{i}\left(\Phi_{i} \geq \hat{\Phi}\right)=\frac{1}{2} \quad \text { and } \quad \mu_{i}\left(\Phi_{i}<\hat{\Phi}\right)=1,
$$

that is, for any quoted price $\Phi_{i} \geq \hat{\Phi}$, the investor believes that marginal production costs are uniformly distributed between 0 and 1 , whereas if a firm quotes $\Phi_{i}<\hat{\Phi}$, then the investor believes that the firm has the highest marginal cost $(c=1)$. We find: 
Proposition 7 A sufficiently small cost-saving, that is, $\gamma \geq 1 / 3$, guarantees that a sequential equilibrium exists: the investor forms beliefs according to equation (14) and each target firm quotes the same acquisition price $\hat{\Phi}=(2 a-1 / 2+\gamma)^{2} / 36$, where $\underline{\Phi}<\hat{\Phi}<\bar{\Phi}$.

\section{Proof: See Appendix A.7.}

An SE always exists for any $\gamma$ when the market is sufficiently small $(a \in[2,4.5])$. If, however, $\gamma$ is small and $a$ is large, then an SE does not exist: underbidding in such a case is profitable even if it implies that the firm will be considered as the highest-cost firm. The reason is that the target's cost is less important for a low $\gamma$, especially as compared to market size $a$. $\hat{\Phi}$ must be larger than the lower bound of the weak PBE so as to make the least-cost firm participate. If $\hat{\Phi}$ were smaller, the least-cost firm would be better off by quoting a higher price: it would not be selected, but due to the belief structure (14), the investor would not change its belief about this firm. The common bid $\hat{\Phi}$ just makes the least-cost firm indifferent and all other types strictly prefer to quote $\hat{\Phi}$.

This indifference leads to the interesting observation that the SE bid is equal to a takeit-or-leave-it-offer of an investor who wants to maximize the acceptance probability of her offer. Suppose that the target firms could accept an offer unilaterally, meaning that they would sell for the offered acquisition price if they were selected by the investor. If an investor does not run an auction but can commit to non-negotiable offers to both firms, an offer of size $\hat{\Phi}$ would be accepted by both firms of all types. Thus, the expected revenue given by the SE coincides with the investor's best take-it-or-leave-it offer that makes unilateral acceptance by both firms certain. Since $\underline{\Phi}<\hat{\Phi}$ the best weak PBE will always do better than the SE for the investor. What about the revenue implications compared to the separating auctions? We find:

Proposition 8 Suppose that Condition 1 and Condition 2 hold and an SE exists in the pooling auction. (i) The SE earns the investor a higher expected payoff than the first-price auction. (ii) A sufficiently small cost-saving, that is, $\gamma \geq 1 / 2$, makes the $S E$ earn the investor also a higher expected payoff than the second-price auction.

Proof: See Appendix A.8.

Proposition 8 shows that the SE outcome is always better for the investor than the outcome of the first-price auction. An immediate implication is that if Condition 1 fails to hold, and thus also the subordinate Condition 2 cannot hold, the pooling auctions 
always do better. The reason is that they do not imply strict adverse selection, and both are not restricted to a certain parameter space. Even if we require consistency, the SE pooling auction dominates the first-price separating auction for this reason. An interesting result is that the SE auction does not always dominate the second-price auction. If Condition 1 and Condition 2 hold, the second-price auction may perform better than the first-price auction because the quoted prices in the second-price auction are determined by the outside options only and the second-price auction does not allow the target firms to appropriate any share of the productivity gains from the acquisition. These outside options are lowest, and thus also the acquisition prices are lowest, the larger is the threat of acquisition-induced productivity gains. While it is true that also $\hat{\Phi}$ declines with a decrease in $\gamma$, an additional effect in the second-price separating auction is that large productivity gains make the adverse selection problem less relevant. For large productivity gains, that is, for a small $\gamma$, the effect of small outside options driving acquisition prices and the increasing irrelevance of the adverse selection problem may make the second-price separating auction more attractive for the investor. The dilemma is that it requires the strongest commitment at the same time.

\section{Concluding remarks}

Our paper has brought together three different strands of the recent auction literature: (i) auctions without enforceable commitment, (ii) auctions with post-auction strategic interactions among agents, and (iii) auctions with externalities. We have shown that both a first-price and a second-price separating auction procedure for firm acquisition will imply strict adverse selection. Furthermore, commitment issues along with information and allocative externalities, due to incomplete cost information and post-auction interaction, may make the takeover procedure via a separating sealed-bid auction not work. However, a pooling auction qualifying for a weak PBE works; serves as a commitment device against ex-post opportunistic behavior; alleviates adverse selection; and even earns the investor a higher expected payoff than a separating takeover procedure if it implies the lowest common bid. If we require consistency, the pooling auction qualifying for a sequential equilibrium is always better than the first-price separating equilibrium. Moreover, there is a threshold level of cost-saving, above which (for sufficiently small cost-saving) a sequential equilibrium is also better than the second-price separating equilibrium.

Our results have shed some light on the potential limitations of (reverse) auctions with 
post-auction interactions. Separating takeover auctions require a substantial degree of commitment in case of downstream information externalities, and if they are run by the investors themselves, opportunistic behavior is hard to avoid.15 Only if the investor outsources the auction activity credibly to an independent party with no own agenda, target firms may develop trust in the allocation and transfer rules. We have also shown that pooling auctions, even with consistency requirements, can do better and can avoid opportunistic behavior. In general, our results have shown that price competition by an auction may be limited under incomplete information and information externalities. Interestingly, the pooling sequential equilibrium secures the investor the same expected revenue as an offer of the investor to the target firms that will make both firms accept the offer unilaterally. This observation shows that changing roles such that the investor becomes the bidder may be a better strategy than running an auction.

We have used the example of a specific reverse auction with linear demands and a uniform cost distribution to demonstrate the limitations and the scope of auctions and their revenue implications. It should be clear that our main results should generalize to any setting in which post-auction activities depend on information revealed during an auction and any separating auction will imply adverse selection. In this case, any separating auction will face the problem that good types could be preferred to be selected ex post over bad types. Thus, any auction that potentially changes downstream interaction may be vulnerable to ex post opportunistic behavior. Examples beyond firm acquisition could include selecting a joint venture or $R \& D$ partner, and competition for an exclusive patent. We leave these extensions to future research.

\section{Appendix}

\section{A.1 Proof of Proposition 1}

$c_{(1)}$ and $c_{(2)}$ are the signals that are rearranged in ascending order: $c_{(1)}<c_{(2)}$. If the design is given, such that the investor acquires the low-cost firm and competes against the high-cost firm, then the investor's ex-ante expected operating profit from acquiring

\footnotetext{
${ }^{15}$ This commitment problem is similar to the one mentioned in Spulber (1990), in which he points out that the bidding behavior and the efficiency of auctions is determined by the contractual commitment in procurement auctions.
} 
the low-cost firm, denoted $\hat{v}^{(1)}\left(c_{(1)}, c_{(2)}\right)$, is equal to

$$
\begin{aligned}
\hat{v}^{(1)}\left(c_{(1)}, c_{(2)}\right) & =\int_{0}^{1}\left(\int_{c_{(1)}}^{1} v^{(1)}\left(c_{(1)}, c_{(2)}\right) d F\left(c_{(2)}\right)\right) d F_{2}\left(c_{(1)}\right) \\
& =\int_{0}^{1} 2\left(1-c_{(1)}\right)\left(\int_{c_{(1)}}^{1} \frac{\left(2 a-\gamma c_{(2)} / 2+2 c_{(2)}-3 \gamma c_{(1)}\right)^{2}}{36\left(1-c_{(1)}\right)} d c_{(2)}\right) d c_{(1)} \\
& =\frac{1}{864}\left(96 a^{2}+128 a(1-\gamma)+57 \gamma^{2}-96 \gamma+48\right),
\end{aligned}
$$

where $v^{(1)}\left(c_{(1)}, c_{(2)}\right)$ is derived from equation (3), and denotes the investor's operating profit after having acquired the low-cost firm. $F_{2}(c)$ is the lowest-order statistics, and given the uniform distribution $F(c)=c$, we can show that $F_{2}(c)=2 F(c)-F(c)^{2}=$ $c(2-c)$. If, however, the design is given, such that the investor acquires the highcost firm and competes against the low-cost firm, then the investor's ex-ante expected operating profit from acquiring the high-cost firm, denoted $\hat{v}^{(2)}\left(c_{(1)}, c_{(2)}\right)$, is equal to

$$
\begin{aligned}
\hat{v}^{(2)}\left(c_{(1)}, c_{(2)}\right) & =\int_{0}^{1}\left(\int_{0}^{c_{(2)}} v^{(2)}\left(c_{(1)}, c_{(2)}\right) d F\left(c_{(1)}\right)\right) d F_{1}\left(c_{(2)}\right) \\
& =\int_{0}^{1} 2 c_{(2)}\left(\int_{0}^{c_{(2)}} \frac{\left(2 a-\gamma\left(1+c_{(1)}\right) / 2+2 c_{(1)}-3 \gamma c_{(2)}\right)^{2}}{36 c_{(2)}} d c_{(1)}\right) d c_{(2)} \\
& =\frac{1}{864}\left(96 a^{2}+64 a(1-4 \gamma)+\gamma(185 \gamma-96)+16\right),
\end{aligned}
$$

where $v^{(2)}\left(c_{(1)}, c_{(2)}\right)$ is derived from equation (3), and denotes the investor's operating profit after having acquired the high-cost firm. $F_{1}(c)=F(c)^{2}=c^{2}$ is the highest-order statistics. We are now ready to show that

$$
\hat{v}^{(1)}\left(c_{(1)}, c_{(2)}\right)-\hat{v}^{(2)}\left(c_{(1)}, c_{(2)}\right)=\frac{1}{27}(2 \gamma+1)(2 a-2 \gamma+1)>0,
$$

which proves the first part of Proposition 1. In the second part of Proposition 1, it is noted that, as to realize $\hat{v}^{(1)}\left(c_{(1)}, c_{(2)}\right)$, no implementable design that leads to truthful revelation exists. We do the proof by contradiction: we assume that there is a design in which the investor learns the types. In such a design, for all possible cost realizations, the low-cost firm is selected and the other firm learns - by not being selected - that the acquired firm has a lower cost. If such a design exists, using the Revelation Principle, we can confine the analysis to a design in which each target firm will send the investor a cost signal that should reveal, in equilibrium, the firm's realized (true) cost. In an implementable design, each target firm truthfully reports its cost-type to the investor. Suppose that a target firm of type $c$ sends cost signal $\tilde{c}$ to the investor. The target firm's expected profit is then given by

$$
\tilde{c}\left(\frac{2 a-\tilde{c}+\gamma \tilde{c}-3 c}{6}\right)^{2}+T(\tilde{c})
$$

where the expression in brackets, derived from equation (2), is the firm's profit when it competes against the lower-cost (acquired) firm, and $T(\tilde{c})$ is the transfer from the 
investor to the target firm that signals type $\tilde{c}$. If the target firm sends cost signal $\tilde{c}$, the probability of being a higher-cost firm (that is, the probability of the other firm being a lower-cost firm) is exactly equal to $\tilde{c}$ : with probability $\tilde{c}$, the firm will not be selected and will realize the profit of a firm competing against a lower-cost firm. At the same time, the firm that is not selected learns that the selected firm has a lower cost than $\tilde{c}$, so the expected ex-post marginal cost of the selected firm - which corresponds to $E_{i}\left(c_{j}\right)$ in equation (2) - is equal to $\tilde{c} \gamma / 2$. Consider now any two different types $c^{\prime}, c^{\prime \prime} \in[0,1]$. If a design exists, it must be incentive compatible, such that neither type has an incentive to mimic the other type:

$$
\begin{aligned}
& I C^{\prime}=c^{\prime}\left(\frac{2 a+c^{\prime} \gamma-4 c^{\prime}}{6}\right)^{2}+T\left(c^{\prime}\right)-\left(c^{\prime \prime}\left(\frac{2 a-c^{\prime \prime}+c^{\prime \prime} \gamma-3 c^{\prime}}{6}\right)^{2}+T\left(c^{\prime \prime}\right)\right) \geq 0, \\
& I C^{\prime \prime}=c^{\prime \prime}\left(\frac{2 a+c^{\prime \prime} \gamma-4 c^{\prime \prime}}{6}\right)^{2}+T\left(c^{\prime \prime}\right)-\left(c^{\prime}\left(\frac{2 a-c^{\prime}+c^{\prime} \gamma-3 c^{\prime \prime}}{6}\right)^{2}+T\left(c^{\prime}\right)\right) \geq 0 .
\end{aligned}
$$

Adding up these two inequalities should also be positive. However, we can show that

$$
I C^{\prime}+I C^{\prime \prime}=-\frac{1}{12}\left(c^{\prime}-c^{\prime \prime}\right)^{2}\left(4 a-(5-2 \gamma)\left(c^{\prime}+c^{\prime \prime}\right)\right)
$$

is definitely negative for sufficiently low cost realizations (and/or for a sufficiently large a). Consequently, any implementable design in which the target firms will truthfully report their cost-types and the low-cost firm will be selected for acquisition will not exist, proving the second part of Proposition 1. Note that Appendix A.2 shows that a mechanism (designed as an auction) will exist if the investor can commit to select the high-cost firm. In that case, the transfer, denoted by $T$ in this section, is equivalent to the expected profit when the firm is selected for acquisition, that is, the probability of being selected times the quoted acquisition price.

\section{A.2 Proof of Proposition 2}

The proof consists of two parts: (i) incentive compatibility and (ii) individual rationality and the development of the optimal bids. As for incentive compatibility, consider two different types - as defined by private (marginal cost) information - $c^{\prime}, c^{\prime \prime} \in[0,1]$. A separating takeover auction must be incentive compatible, such that neither type has an incentive to mimic the other type:

$$
\begin{aligned}
I C^{\prime}= & c^{\prime} \phi^{\prime}+\left(1-c^{\prime}\right)\left(\frac{2 a+\gamma\left(1+c^{\prime}\right)-4 c^{\prime}}{6}\right)^{2} \\
& -\left(c^{\prime \prime} \phi^{\prime \prime}+\left(1-c^{\prime \prime}\right)\left(\frac{2 a-c^{\prime \prime}+\gamma\left(1+c^{\prime \prime}\right)-3 c^{\prime}}{6}\right)^{2}\right) \geq 0, \\
I C^{\prime \prime}= & c^{\prime \prime} \phi^{\prime \prime}+\left(1-c^{\prime \prime}\right)\left(\frac{2 a+\gamma\left(1+c^{\prime \prime}\right)-4 c^{\prime \prime}}{6}\right)^{2} \\
& -\left(c^{\prime} \phi^{\prime}+\left(1-c^{\prime}\right)\left(\frac{2 a-c^{\prime}+\gamma\left(1+c^{\prime}\right)-3 c^{\prime \prime}}{6}\right)^{2}\right) \geq 0 .
\end{aligned}
$$


Adding up the two inequalities, given by equations A.1 and A.2 , leads to

$$
I C^{\prime}+I C^{\prime \prime}=\frac{1}{12}\left(c^{\prime}-c^{\prime \prime}\right)^{2}\left(4 a-(5-2 \gamma)\left(c^{\prime}+c^{\prime \prime}\right)+2\right)
$$

which is clearly positive for any $c^{\prime}, c^{\prime \prime}, \gamma \in[0,1]$, given $a>2$. Hence, the sufficient condition for incentive compatibility is fulfilled.

We now turn to the optimal bids and individual rationality. If Condition 1 is fulfilled, firm $i$ will win the auction by quoting $\phi_{i}<\phi_{j}$, and will be paid $\phi_{i}$. We denote by $\Psi_{i}$ the probability that firm $i$ wins the auction (that is, the probability that $\phi_{i}<\phi_{j}$ ). By the same token, the other firm wins the auction with complementary probability $\left(1-\Psi_{i}\right.$ ) (that is, the probability that $\phi_{i}>\phi_{j}$ ). If firm $j$ wins the auction, firm $i$ will have to compete against the investor in a Cournot duopoly, and its profit follows from equation (2), where $E_{j}\left(c_{i}\right)=\Psi_{i}\left(\phi_{i}\right)$ and $E_{i}\left(c_{j}\right)=\gamma\left(1+\Psi_{i}\left(\phi_{i}\right)\right) / 2$. Firm $i$ 's probability to win the auction $\Psi_{i}\left(\phi_{i}\right)$ is determined by firm $i$ 's productivity signal. Provided Condition 1 is fulfilled, if the investor acquires firm $j$, firm $i$ updates its belief about firm $j$ 's productivity such that $E_{i}\left(c_{j}\right)=\gamma \int_{\Psi_{i}}^{1}\left(c_{j} /\left(1-\Psi_{i}\right)\right) d c_{j}=\gamma\left(1+\Psi_{i}\right) / 2$, since the investor would have acquired firm $j$ only if firm $j$ had quoted a lower price, that is, only if firm $j$ 's cost signal had been higher than that of firm $i$. By the same token, in equilibrium, $E_{j}\left(c_{i}\right)=\Psi_{i}\left(\phi_{i}\right)$, since the investor, acquiring firm $j$, observes the bid of the other firm, and so can invert the bidding function. If the firms bid according to their true productivity, then $E_{j}\left(c_{i}\right)=c_{i}$. Firm $i$ 's expected profit, denoted $\hat{\pi}^{a}\left(c_{i}\right)$ where superscript $a$ stands for the auction outcome, is thus equal to

$$
\hat{\pi}^{a}\left(c_{i}\right)=\Psi_{i}\left(\phi_{i}\right) \phi_{i}+\left(1-\Psi_{i}\left(\phi_{i}\right)\right)\left(\frac{2 a-\Psi_{i}\left(\phi_{i}\right)+\gamma\left(1+\Psi_{i}\left(\phi_{i}\right)\right)-3 c_{i}}{6}\right)^{2},
$$

where $\Psi_{i}\left(\phi_{i}\right)$ coincides with the inverse of the price function. The price function $\phi_{i}\left(\Psi_{i}\right)$ specifies firm $i$ 's price demand, where $\Psi_{i}$ represents firm $i$ 's signal. Incentive compatibility requires $\phi_{i}\left(\Psi_{i}\right) \equiv \phi_{i}\left(\Psi_{i}=c_{i}\right),{ }^{16}$

Firm $i$ has to quote a price that maximizes the expected profit given by equation (A.3). We simplify the notation by expressing equations without subscript $i$. The first-order condition, $\partial \pi(\phi) / \partial \phi=0$, is equal to

$$
\Psi(\phi)+\frac{\partial \Psi(\phi)}{\partial \phi}\left(\begin{array}{l}
\phi-\left(\frac{2 a-\Psi(\phi)+\gamma(1+\Psi(\phi))-3 c}{6}\right)^{2} \\
-(1-\Psi(\phi))(1-\gamma)\left(\frac{2 a-\Psi(\phi)+\gamma(1+\Psi(\phi))-3 c}{18}\right)
\end{array}\right)=0
$$

We assume that both firms follow the same strategy $\phi(c)$, which is strictly decreasing in a firm's marginal cost and has a well-defined inverse function. In equilibrium, the inverse of a firm's price function is equal to the firm's marginal cost.

\footnotetext{
${ }^{16}$ In contrast to Jehiel and Moldovanu (2000) and Koska (2016), we do not assume revelation of firms' private information after the auction and before product market interactions occur.
} 
Substituting $c \equiv \Psi(\phi(c))$ into the first-order condition gives

$$
\Psi(\phi)+\frac{\partial \Psi(\phi)}{\partial \phi}\left(\begin{array}{l}
\phi-\left(\frac{2 a+\gamma(1+\Psi(\phi))-4 \Psi(\phi)}{6}\right)^{2} \\
-(1-\Psi(\phi))(1-\gamma)\left(\frac{2 a+\gamma(1+\Psi(\phi))-4 \Psi(\phi)}{18}\right)
\end{array}\right)=0
$$

where $\Psi(\bar{\phi}) \equiv 0$ such that $\bar{\phi} \equiv(2 a+\gamma)^{2} / 36+(2 a+\gamma) / 18$. Note that $\bar{\phi}$ is the maximum price that the most efficient firm quotes in equilibrium. We can use equation (A.4) to characterize the firms' quoted prices in equilibrium. Rewriting equation (A.4) as a differential equation,

$$
-\phi^{\prime}(c)=\frac{1}{c}\left(\begin{array}{l}
\phi(c)-\left(\frac{2 a+\gamma(1+c)-4 c}{6}\right)^{2} \\
-(1-c)(1-\gamma)\left(\frac{2 a+\gamma(1+c)-4 c}{18}\right)
\end{array}\right)
$$

and, by including the boundary condition $\phi(0)=(2 a+\gamma)^{2} / 36+(2 a+\gamma) / 18$, solving for $\phi(c)$ gives the optimal price function:

$$
\phi^{*}(c, \gamma)=\underbrace{\frac{\left(2 a^{2}+2 a+4 c^{2}-5 a c-2 c\right)}{18}}_{\phi^{*}(c, \gamma=0)}+\underbrace{\gamma \frac{\left(2+4 a c-6 c^{2}-\left(1-c-c^{2}\right) \gamma\right)}{36}}_{\gamma \Delta(c, \gamma)} .
$$

Individual rationality is guaranteed: a firm's expected profit when it participates in the auction, $c \phi^{*}(c, \gamma)+(1-c)(2 a+(1+c) \gamma-4 c)^{2} / 36$, is larger than its expected profit when it stays away from the auction, $(2 a-(1 / 2)+\gamma-3 c)^{2} / 36$. A firm can manipulate the post-auction market game by participating in the auction, and by pretending to be the lowest-cost firm $\left(c^{\prime \prime}=0\right.$ or $c^{\prime}=0$ in equations (A.1) and (A.2), respectively) which of course leads to a larger expected outside profit, $(2 a+\gamma-3 c)^{2} / 36$. Even in this case, $c \phi^{*}(c, \gamma)+(1-c)(2 a+(1+c) \gamma-4 c)^{2} / 36>(2 a+\gamma-3 c)^{2} / 36$, provided $a>2$.

\section{A.3 Proof of Proposition 3}

Recall that $V^{i}\left(c_{i}, c_{j}\right), i \neq j \in\{1,2\}$, given by equation (7), denotes the investor's expected profit after having acquired firm $i$ and when competing against firm $j$. Firms quote prices $\phi^{*}\left(c_{i}\right), i \in\{1,2\}$, in equilibrium, following the price function, given by Proposition 2. The investor's commitment on acquiring the higher-cost firm is credible only if the investor acquires firm $i$ when firm $i$ 's quoted price is less than the price quoted by the other firm.

Let us suppose that firm $i$ 's marginal cost is larger than that of firm $j$, such that $c_{i}>c_{j}, i \neq j \in\{1,2\}$, implying firm $i$ and firm $j$ will quote prices in equilibrium such that $\phi^{*}\left(c_{i}\right)<\phi^{*}\left(c_{j}\right), i \neq j \in\{1,2\}$. We need to prove that $V^{i}\left(c_{i}, c_{j}\right)>V^{j}\left(c_{i}, c_{j}\right)$, $i \neq j \in\{1,2\}$, that is, the investor will acquire firm $i$ in such a situation, even without binding commitment, which makes the auction self-enforcing. Equation A.5 gives the difference between $V^{i}\left(c_{i}, c_{j}\right)$ and $V^{j}\left(c_{i}, c_{j}\right)$ :

$$
V^{i}\left(c_{i}, c_{j}\right)-V^{j}\left(c_{i}, c_{j}\right)=\frac{1}{144}\left(c_{i}-c_{j}\right)(\alpha+\beta C) ; \quad i \neq j \in\{1,2\},
$$


where $C=c_{i}+c_{j}, \alpha=16+8 a+8 \gamma-56 a \gamma+6 \gamma^{2}$, and $\beta=-48+\gamma(32+31 \gamma)$.

Equation A.5 shows that $V^{i}\left(c_{i}, c_{j}\right)>V^{j}\left(c_{i}, c_{j}\right)$ only if $(\alpha+\beta C)>0$, given $c_{i}>c_{j}$. We can see that $\partial(\alpha+\beta C) / \partial C<0$ if $\gamma<0.831$. Let us start from the case $\gamma>0.831$, so $\partial(\alpha+\beta C) / \partial C>0$. It is obvious that $V^{i}\left(c_{i}, c_{j}\right)-V^{j}\left(c_{i}, c_{j}\right)=0$ if $C=\widetilde{C}$, where $\widetilde{C}=-\alpha / \beta$. Also, it is straightforward to show that $\widetilde{C}>2$ for any given $a>2$, and for $\gamma \in[0.831,1]$. Therefore, for all $c_{i} \in[0,1], i=\{1,2\}, C<\widetilde{C}$, implying that $V^{i}\left(c_{i}, c_{j}\right)-V^{j}\left(c_{i}, c_{j}\right)<0$. The investor's profit will be larger if she acquires the lowercost firm. So the investor's commitment is not credible given that $\gamma$ is sufficiently large such that $\gamma>0.831$. If, however, $\gamma<0.831$, then $\partial(\alpha+\beta C) / \partial C<0$. In this case, we can see that $\widetilde{C}<0<C$ for all $c_{i} \in[0,1], i=\{1,2\}$, for any given $a>2$, and for $\gamma \in[0.313,0.831]$. Consequently, the investor fails to commit credibly on acquiring the higher-cost firm when $\gamma \in[0.313,0.831]$, or rather, when $\gamma \in[0.313,1]$.

As for $\gamma \in[0,0.313]$ at which $\partial(\alpha+\beta C) / \partial C<0$, we find that $\widetilde{C}<0<C$. The investor fails to commit credibly on acquiring the higher-cost firm, especially for some constellations of parameter values of $a$ and $\gamma$ (Region I in Figure 1). Similarly, we find that $\widetilde{C}>2>C$ in Region III, illustrated by Figure 1 , so the auction is self-enforcing in this region. As is illustrated by Figure $1, \widetilde{C} \in[0,2]$ in Region II: the investor's ex post behavior depends on the value of $C$. In Region II, the investor wants to acquire the lower-cost firm if the average industry marginal cost before the acquisition of a firm takes place, $C / 2$, is sufficiently large, such that $C>\widetilde{C}$. Although a separating takeover auction can be self-enforcing if $C<\widetilde{C}$, the firms do not know the average industry marginal cost at the time of the auction. Consequently, a separating takeover auction does not work in Region II.

\section{A.4 Proof of Proposition 4}

The difference between equations $(9)$ and $(6)$ is equal to

$$
\frac{1}{108}(1-\gamma)(8 a+5 \gamma-4) \geq 0
$$

for any $\gamma \in[0,1]$ and $a>2$.

\section{A.5 Proof of Proposition 5}

Suppose that a target firm quotes a higher acquisition price $\Phi^{\prime}>\Phi^{*}$. This higher acquisition price will make sure that this target firm will not be selected. The reason is simple. First, the acquisition price is higher; and second, the investor believes now that it will face a weak rival after having acquired the other firm. The expected profit of the target firm quoting $\Phi^{\prime}$, denoted $\hat{\pi}^{p \prime}\left(c_{i}\right)$, and that of the target firm quoting $\Phi^{*}$, 
denoted $\hat{\pi}^{p}\left(c_{i}\right)$ and given by equation (12), are compared in equation (A.6):

$$
\begin{aligned}
\hat{\pi}^{p \prime}\left(c_{i}\right)=\left(\frac{2 a-1+\gamma-3 c_{i}}{6}\right)^{2} & \leq \hat{\pi}^{p}\left(c_{i}\right)=\frac{1}{2} \Phi^{*}+\frac{1}{2}\left(\frac{2 a-1 / 2+\gamma-3 c_{i}}{6}\right)^{2} \\
\Leftrightarrow \Phi^{*} & \geq \frac{\left(2 a-1+\gamma-3 c_{i}\right)^{2}}{18}-\frac{\left(2 a-1 / 2+\gamma-3 c_{i}\right)^{2}}{36},
\end{aligned}
$$

where the inequalities are the condition that this defection option is not be profitable. This defection option should not be profitable for any cost-type. To determine the relevant condition, we define

$$
\Lambda\left(c_{i}\right) \equiv \frac{\left(2 a-1+\gamma-3 c_{i}\right)^{2}}{18}-\frac{\left(2 a-1 / 2+\gamma-3 c_{i}\right)^{2}}{36},
$$

where $d \Lambda / d c_{i}=-(4 a-6 c+2 \gamma-3) / 12$ and $d^{2} \Lambda / d c_{i}^{2}=1 / 2$, showing that $\Lambda\left(c_{i}\right)$ is convex in $c_{i}$. Thus, the maximum of $\Lambda$ is either $\Lambda(0)$ or $\Lambda(1)$. We can show that

$$
\Lambda(0)-\Lambda(1)=\frac{1}{6}(2 a+\gamma-3)>0
$$

because $a>2$. Thus, we find that the condition given by equation A.6 holds for all cost-types if it is satisfied for the most productive firm, $c_{i}=0$ :

$$
\Phi^{*} \geq \frac{(2 a-1+\gamma)^{2}}{18}-\frac{(2 a-1 / 2+\gamma)^{2}}{36} .
$$

Now suppose that the target firm quotes a lower acquisition price $\Phi^{\prime \prime}<\Phi^{*}$. The investor has the option to accept this lower offer, but at the same time she updates her beliefs, such that she assumes that this is now a target firm with the highest marginal production cost, which is equal to 1 . A remark on the rival firm is in order when this lower bid is accepted by the investor. Since bids are not revealed, the firm that is not selected by the investor will not be able to learn whether or not the winning bid was a deviation; therefore it will continue to assume that the firm that is selected by the investor has an expected cost realization of $1 / 2$, which leads to the expected ex-post marginal cost of the acquired firm $\gamma / 2$. Therefore, the investor's expected payoff from accepting the lower offer, denoted $\hat{V}^{p \prime \prime}\left(\Phi^{\prime \prime}\right)$, is equal to

$$
\hat{V}^{p \prime \prime}\left(\Phi^{\prime \prime}\right)=\left(\frac{2 a-7 \gamma / 2+1}{6}\right)^{2}-\Phi^{\prime \prime}+\Gamma,
$$

which we can compare with her expected payoff from rejecting $\Phi^{\prime \prime}$ (in which case she will update her beliefs accordingly) and accepting $\Phi^{*}$, denoted $\hat{V}^{p \prime \prime}\left(\Phi^{*}\right)$ and given by

$$
\hat{V}^{p \prime \prime}\left(\Phi^{*}\right)=\int_{0}^{1}\left(\frac{2 a-\gamma / 2+2-3 \gamma c}{6}\right)^{2} d c-\Phi^{*}+\Gamma=\frac{(2 a+2-2 \gamma)^{2}}{36}+\frac{\gamma^{2}}{48}-\Phi^{*}+\Gamma \text {. }
$$

A lower offer makes sense only if it will be accepted by the investor. Otherwise, the target firm loses, not only because the lower offer is declined, but also it will be considered as the highest-cost firm by the investor. The investor will accept the lower offer $\Phi^{\prime \prime}$ if $\hat{V}^{p \prime \prime}\left(\Phi^{\prime \prime}\right)>\hat{V}^{p \prime \prime}\left(\Phi^{*}\right)$ which is the case when

$$
\Phi^{\prime \prime}<\Phi^{*}-\left(\frac{(2 a+2-2 \gamma)^{2}}{36}+\frac{\gamma^{2}}{48}-\frac{(2 a-7 \gamma / 2+1)^{2}}{36}\right) .
$$


At the same time, $\Phi^{\prime \prime}$ must be large enough to make the defecting firm better off such that $\Phi^{\prime \prime}>\hat{\pi}^{p}\left(c_{i}\right)$, where $\hat{\pi}^{p}\left(c_{i}\right)$ is given by equation 12 . Thus, we conclude that no target firm of any cost-type has an incentive to quote a lower acquisition price if

$$
\begin{aligned}
\hat{\pi}^{p}\left(c_{i}=1\right) & =\frac{1}{2} \Phi^{*}+\frac{1}{2}\left(\frac{2 a-7 / 2+\gamma}{6}\right)^{2} \\
& \geq \Phi^{*}-\left(\frac{(2 a+2-2 \gamma)^{2}}{36}+\frac{\gamma^{2}}{48}-\frac{(2 a-7 \gamma / 2+1)^{2}}{36}\right) \\
\Leftrightarrow \Phi^{*} & \leq \frac{(2 a+2-2 \gamma)^{2}}{18}+\frac{\gamma^{2}}{24}-\frac{(2 a-7 \gamma / 2+1)^{2}}{18}+\frac{(2 a-7 / 2+\gamma)^{2}}{36} .
\end{aligned}
$$

Note that $\hat{\pi}^{p}\left(c_{i}\right)$, given by equation (12), increases with a decrease in $c_{i}$. Therefore, if the acquisition price that would be accepted by the investor $\left(\Phi^{\prime \prime}\right)$ is too small even for the least productive target firm, such that $\hat{\pi}^{p}\left(c_{i}=1\right)>\Phi^{\prime \prime}$, then it is not profitable for any firm to deviate. In summary, we can use the two conditions that are given by equations A.7 and A.8, respectively, to show that a pooling equilibrium exists if these two conditions

$$
\begin{aligned}
& \Phi^{*} \leq \frac{(2 a+2-2 \gamma)^{2}}{18}+\frac{\gamma^{2}}{24}-\frac{(2 a-7 \gamma / 2+1)^{2}}{18}+\frac{(2 a-7 / 2+\gamma)^{2}}{36} \equiv \bar{\Phi}, \\
& \Phi^{*} \geq \frac{(2 a-1+\gamma)^{2}}{18}-\frac{(2 a-1 / 2+\gamma)^{2}}{36} \equiv \underline{\Phi}
\end{aligned}
$$

hold at the same time, where $\bar{\Phi}-\underline{\Phi}=(2 \gamma(4 a-5 \gamma-2)+11) / 24>0$ for any $\gamma \in[0,1]$ and $a>2$. This completes the proof that pooling equilibria exist, such that each target firm quotes the same acquisition price $\Phi^{*} \in[\underline{\Phi}, \bar{\Phi}]$.

\section{A.6 Proof of Proposition 6}

The difference between equations $(13)$ and $(9)$ is equal to

$$
\frac{1}{288}(16 a+10+\gamma(32 a-8-17 \gamma))>0
$$

for any $\gamma \in[0,1]$ and $a>2$.

This shows that the best weak PBE earns the investor a higher expected payoff than the second-price separating auction, and since the second-price separating auction earns the investor a higher expected payoff than the first-price separating auction (see Proposition 4), our proof is complete.

\section{A.7 Proof of Proposition 7}

Any SE must allow for a range of bids in which the belief structure is consistent. The upper bound $\bar{\Phi}$ results from the same line of reasoning as in the case of a weak PBE: it should not be more profitable for any firm to be regarded as a high-cost firm successfully 
underbidding the candidate equilibrium bid such that the investor would prefer this bid. This puts an upper bound on the bid as in the weak PBE. However, this is only a bound for the belief structure in the SE, and the equilibrium bid is unique, belongs also to the set of equilibrium bids of the weak PBE, but is larger than the lowest bid supported by a weak PBE. The reason is competition in the range in which the belief structure is given by the priors.

Suppose that both firms bid $\tilde{\Phi}$ where $\hat{\Phi}<\tilde{\Phi}$. The investor will immediately accept a marginally lower bid by any of the two firms because it does not change its belief structure and she can get a target firm for a cheaper price. The immediate implication is that bids work in a Bertrand manner in this range so that an equilibrium must imply $\Phi_{i}=\hat{\Phi}$. At the same time, however, it should also not be profitable to quote a higher price in this range. A firm doing so will not change the belief structure of the investor, and while this firm will not be selected, it may be better off if the stand-alone profit is larger than the expected profit of competing against the rival for a partnership with the investor. Thus, the lower bound is now determined by the condition that $\hat{\pi}^{p}\left(c_{i}\right)$ (see equation (12)) should not be smaller than the stand-alone profit under unrevised investor beliefs, that is $\left(2 a-1 / 2+\gamma-3 c_{i}\right)^{2} / 36$. It is then straightforward to see that this constraint is fulfilled if it is met by the least-cost type $c_{i}=0$, leading to $\hat{\Phi}$ as the equilibrium bid.

Along with consistency of beliefs discussed above, an SE requires that a sequence of purely mixed strategies exists such that the limit of this sequence is the SE. ${ }^{17}$ Consider the following purely mixed strategies of each firm: choose $\hat{\Phi}$ with probability $\sigma_{n}=$ $1-(1 / n)$ and $\Phi_{i}$ with probability $1-\sigma_{n}=(1 / n)$ where $\hat{\Phi}<\Phi_{i}$ and $n \in \mathbb{N}$.

Thus, we define a sequence

$$
\left(\sigma_{n}, \mu_{n}\right)=\left(1-\frac{1}{n}, \frac{1}{2}\right)
$$

The (constant) sequence of beliefs is consistent with the belief structure: as long as all bids are in the relevant range, the investor will stick to her priors.

A sufficient condition for $\hat{\Phi}<\bar{\Phi}$ is $\gamma \geq 1 / 3$ which guarantees existence of an SE because $\lim _{n \rightarrow \infty}\left(\sigma_{n}, \mu_{n}\right)=(1,1 / 2)$ : a sequence exists that converges to the candidate equilibrium, and since the strategies are optimal given beliefs and the beliefs are derived from Bayes' Rule for the optimal strategies, our proof for the SE is complete.

\footnotetext{
${ }^{17}$ Note carefully that the equilibrium is not perfect as it does not imply Nash behavior at all nodes off the equilibrium path. A perfect Bayesian equilibrium is also a sequential equilibrium and vice versa if either player has at most two types or the sequence of the game is limited to two stages (Fudenberg and Tirole, 1991), but our model does not meet any of these two conditions.
} 


\section{A.8 Proof of Proposition 8}

Replacing $\Phi^{*}$ in equation $(11)$ with $\hat{\Phi}$, given by Proposition 7, yields the investor's expected profit from firm acquisition via an SE pooling auction such that

$$
\frac{1}{48}(1+a(8-16 \gamma)+\gamma(5 \gamma-4))+\Gamma .
$$

The difference between equations $(\mathrm{A.9})$ and $(6)$ is equal to

$$
\frac{1}{864}\left(16 a(2 \gamma+1)-91 \gamma^{2}+34\right)>0,
$$

for any $\gamma \in[0,1]$ and $a>2$, which proves the first part of Proposition 8 .

The difference between equations $(\mathrm{A} .9)$ and $(9)$ is equal to

$$
\frac{1}{288}(16 a(2 \gamma-1)-\gamma(17 \gamma+24)+22)
$$

which is clearly positive for any $\gamma \in[1 / 2,1]$ and $a>2$, which proves the second part of Proposition 8. As is clear from the equation above, $\gamma \geq 1 / 2$ is only a sufficient condition for payoff dominance of the SE. In particular, we can solve for the threshold $\gamma$ (as a function of $a>2$ ) at which the equation above is equal to zero, and hence above which the SE earns the investor a higher expected payoff than the second-price separating auction.

\section{References}

[1] Andrade, G., Mitchell, M., Stafford, E. 2001. New evidence and perspectives on mergers. Journal of Economic Perspectives 15(2), 103-120.

[2] Boone, A.L., Mulherin, J.H. 2007. How are firms sold? Journal of Finance 62(2), $847-875$.

[3] Bulow, J., Geanakoplos J., Klemperer P. 1985. Multimarket oligopoly: strategic substitutes and complements. Journal of Political Economy 93(3): 488-511.

[4] Bulow, J., Klemperer, P. 1996. Auctions versus negotiations. American Economic Review, 86(1), 180-194.

[5] Deneckere, R., Davidson, C. 1985. Incentive to form coalitions with Bertrand competition. Rand Journal of Economics 16(4), 473-486.

[6] Ding, W., Fan, C., Wolfstetter, E.G. 2013. Horizontal mergers with synergies: cash vs. profit-share auctions. International Journal of Industrial Organization 31(5), 382-391.

[7] Farrell, J., Shapiro C. 1990. Horizontal mergers: an equilibrium analysis. American Economic Review 80(1), 107-126. 
[8] Freixas, X., Guesnerie, R., Tirole, J. 1985. Planning under incomplete information and the ratchet effect. Review of Economic Studies 52(2), 173-192.

[9] Fudenberg D., Tirole J. 1991. Perfect Bayesian and Sequential Equilibrium. Journal of Economic Theory. 53: 236-260.

[10] Goeree, J.K. 2003. Bidding for the future: signaling in auctions with an aftermarket. Journal of Economic Theory 108(2), 345-364.

[11] Gugler, K., Mueller, D.C., Yurtoglu, B.B., Zulehner, C. 2003. The effects of mergers: an international comparison, International Journal of Industrial Organization, $21,625-653$.

[12] Gupta, M., Lebrun, B. 1999. First-price auctions with resale. Economics Letters 64(2), 181-185.

[13] Hafalir, I., Krishna, V. 2008. Asymmetric auctions with resale. American Economic Review 98(1), 87-112.

[14] Hafalir, I., Krishna, V. 2009. Revenue and efficiency effects of resale in first-price auctions. Journal of Mathematical Economics 45(9-10), 589-602.

[15] Haile, P.A. 2003. Auctions with private uncertainty and resale opportunities. Journal of Economic Theory 108(1), 72-110.

[16] Hennessy, D.A. 2000. Cournot oligopoly conditions under which any horizontal merger is profitable. Review of Industrial Organization 17(3), 277-284.

[17] Hoppe, H.C., Jehiel, P., Moldovanu, B. 2006. License auctions and market structure. Journal of Economics 85 Management Strategy 15(2), 371-396.

[18] Janssen, M.C.W., Karamychev, V.A. 2010. Do auctions select efficient firms? Economic Journal 120(549), 1319-1344.

[19] Janssen, M.C.W, Moldovanu, B. 2004. Allocation mechanisms and post-allocation interaction, in: Janssen M.C.W. (Ed.), Auctioning public assets: analysis and alternatives, Cambridge Univ.Press, Cambridge, pp. 130-146.

[20] Jehiel, P., Moldovanu, B. 2000. Auctions with downstream interaction among buyers. Rand Journal of Economics 31(4), 768-791.

[21] Jehiel, P., Moldovanu, B. 2003. An economic perspective on auctions. Economic Policy 18(36), 269-308.

[22] Jehiel, P., Moldovanu, B. 2006. Allocative and informational externalities in auctions and related mechanisms, in: Blundell, R., Newey W.K., Persson, T. (eds.), Advances in Economics and Econometrics: Theory and Applications, The Proceedings of the 9th World Congress of the Econometric Society, Cambridge University Press, Cambridge, pp. 102-135.

[23] Jehiel, P., Moldovanu, B., Stacchetti, E. 1996. How (not) to sell nuclear weapons. American Economic Review 86(4), 814-829. 
[24] Jehiel, P., Moldovanu, B., Stacchetti, E. 1999. Multidimensional mechanism design for auctions with externalities. Journal of Economic Theory 85(2), 258-293.

[25] Klemperer, P. 1999. Auction theory: a guide to the literature. Journal of Economic Surveys 13(3), 227-286.

[26] Klemperer, P. 2004. Auctions: theory and practice, Princeton University Press, Princeton.

[27] Koska, O.A. 2016. A consumer-surplus standard in merger approvals, foreign direct investment, and welfare. Mimeo.

[28] Koska, O.A., Stähler, F. 2014. Optimal acquisition strategies in unknown territories. Journal of Institutional and Theoretical Economics 170(3), 406-426.

[29] Krishna, V. 2002. Auction theory, Academic Press, San Diego.

[30] Laffont, J.J., Tirole, J. 1988. The dynamics of incentive contracts. Econometrica 56(5), 1153-1175.

[31] Lommerud, K.E., Sorgard, L. 1997. Merger and product range rivalry. International Journal of Industrial Organization 16(1), 21-42.

[32] Manelli A.M., Vincent D.R. 1995. Optimal procurement mechanisms. Econometrica $63(3), 591-621$.

[33] Myerson, R. 1981. Optimal auction design. Mathematics of Operations Research $6(1), 58-73$.

[34] Pagnozzi, M., Rosato, A. 2016. Entry by Takeover: Auctions vs. Bilateral Negotiations. International Journal of Industrial Organization 44(1), 68-84.

[35] Perry, M.K., Porter, R.H. 1985. Oligopoly and the incentive for horizontal merger. American Economic Review 75(1), 219-227.

[36] Raff, H., Ryan, M., Stähler, F. 2012. Firm productivity and the foreign-market entry decisions. Journal of Economics 86 Management Strategy 21(3), 849-871.

[37] Salant, S., Switzer, S., Reynolds, R.J. 1983. Losses from horizontal merger: the effects of an exogenous change in industry structure on Cournot-Nash equilibrium. Quarterly Journal of Economics 98(2), 185-199.

[38] Skreta, V. 2015. Optimal auction design under non-commitment. Journal of Economic Theory, 159(2), 854-890.

[39] Spulber, D.F. 1990. Auctions and Contract Enforcement. Journal of Law, Economics, 6 Organization 6(2), 325-344.

[40] UNCTAD 2014. World Investment Report 2014. United Nations, New York.

[41] Vartiainen, H. 2013. Auction Design without Commitment. Journal of the European Economic Association 11(2), 316-342. 